\title{
Genotype/phenotype correlations in type 2 neurofibromatosis (NF2): evidence for more severe disease associated with truncating mutations
}

\author{
D G R Evans, L Trueman, A Wallace, S Collins, T Strachan
}

\begin{abstract}
Blood samples from 125 unrelated families with classical type 2 neurofibromatosis (NF2) with bilateral vestibular schwannomas have been analysed for mutations in the NF2 gene. A further 17 families fulfilling modified criteria for NF2 have also been analysed. Causative mutations have been identified in 54 (43\%) classical families and six (35\%) of those fulfilling modified criteria. Forty-two cases from 38 families with truncating mutations had an average age at onset of symptoms of 19 years and diagnosis at 22.4 years. Fifty-one cases from 16 families with splice site mutations (15 from six), missense mutations (18 from six), and large deletions (18 from five) had an average age of onset of 27.8 years and at diagnosis of 33.4 years. Subjects with truncating mutations were significantly more likely to have symptoms before 20 years of age $(p<0.001)$ and to develop at least two symptomatic CNS tumours in addition to vestibular schwannoma before 30 years $(p<0.001)$. There were also significantly fewer multigenerational families with truncating mutations. Four further truncating mutations were in mosaic form and were associated with milder disease than other similar mutations.
\end{abstract}

This large study has confirmed the previous impression that truncating mutations are associated with severe disease, but caution has to be exercised in using mutation type to predict disease course. $(7$ Med Genet 1998;35:450-455)

Medical Genetics, St

Mary's Hospital, Manchester M13 0JH, UK

D G R Evans

A Wallace

University

Department of Human

Genetics, Newcastle

University, Newcastle

upon Tyne, UK

L Trueman

S Collins

T Strachan

Correspondence to: Dr Evans.

Received 5 September 1997 Revised version accepted for publication

12 December 1997

2 neurofibromatosis (NF2) is an somal dominantly inherited condition characterised by the development of bilateral vestibular schwannomas, schwannomas of other cranial, spinal, and cutaneous nerves, and cranial and spinal meningiomas. ${ }^{1-3}$ In 1987 , the National Institutes of Health Consensus Meeting set out firm diagnostic criteria for NF2. ${ }^{4}$ These criteria meant that any person with bilateral vestibular schwannomas was assumed to have the disease and that $50 \%$ of offspring would be predicted to be affected. The NF2 gene was isolated in $1993^{56}$ and there have been a number of reports of germline mutations in large series of affected cases since that time. ${ }^{7-9}$ Although detection rates using SSCP or DGGE have in general been disappointingly low, even in classically affected people, some evidence for a genotype/phenotype correlation appears to be emerging. ${ }^{8-10}$ We report here for the first time the largest single study of correlations between mutational type and disease phenotype in NF2.

\section{Patients and methods}

Subjects with classical NF2 (bilateral VS) have been ascertained by our centres since 1989 . Blood samples have been obtained from affected subjects from 125 unrelated families. Clinical data have been meticulously sought and most families have been seen by the corresponding author (91/125). Full information including scan data was available on 201 subjects from the 125 families. Patients who had died before the study were excluded from the main analysis. Data specifically recorded were: age at onset of the first clearly related symptom from a CNS tumour, age at diagnosis of bilateral vestibular schwannomas (VS), or NF2 and the presence of other non-VS tumours either symptomatic or on scan. Although age at onset of cutaneous tumours was sought, this was not included as representing a first symptom. Although cutaneous tumours are associated with more severe disease, ${ }^{23}$ they may occur many years before the onset of significant CNS tumours and very rarely contribute in themselves to disease severity. Many patients also find it hard to recollect accurately when they first noticed a skin tumour. Ophthalmic data were also collected; however, age at onset of a cataract was also excluded as representing a first symptom. Cataracts again are rarely a cause of serious morbidity in NF2 and are often found incidentally at routine eye checks. Disease severity in $\mathrm{NF} 2$ is related to early onset, number, and growth rate of CNS tumours. Therefore the following details were analysed. (1) Age at
(1) Unilateral VS or

(2) Any two of: meningioma, glioma, neurofibroma, Additional criteria

Unilateral VS + (2)

Multiple meningioma ( 2 or more) + unilateral VS or any 2 of: glioma, neurofibroma, schwannoma, cataract schwannoma, posterior subcapsular lenticular opacities 
onset of first CNS tumour related symptom. (2) Age at onset of hearing loss. (3) Age at diagnosis of NF2 (excluding DNA diagnosis alone). (4) Number of symptomatic tumours. (5) Presence of 10 or more tumours $>0.5 \mathrm{~cm}$ on MRI scan.

Families were arbitrarily categorised as mild, intermediate, or severe on the basis of having presented after 30 years, between 20 and 30 years, or before 20 years. Those subjects presenting before 30 years, but who had fewer than three other non-VS symptomatic tumours by 30 years of age, were considered mildly affected. These criteria have been modified slightly from our previous publication $\mathrm{s}^{23}$ and some families on re-evaluation have been reclassified (for example, family 60). All subjects had undergone cranial imaging with MRI and the majority had undergone full spinal imaging. Any person with more than 10 tumours $>0.5 \mathrm{~cm}$ on scan was considered severely affected. As previous classifications have been arrived at before the ability to detect tiny $(1-2 \mathrm{~mm})$ tumours, some modification is necessary if scan data are to be included. Current evidence would suggest that $75-90 \%$ of NF2 cases will have evidence of spinal tumours on MRI. ${ }^{811}$ Many of these tumours will remain small and never become symptomatic. As a measure of severity, only tumours $>0.5 \mathrm{~cm}$ have therefore been included. The great majority of patients have had some form of ophthalmological assessment. While this involved slit lamp examination, in most cases full assessment for retinal hamartomas and other features such as epiretinal membranes was sparse.

In addition to the 125 classical families, samples from 17 subjects fulfilling modified criteria for NF2 (table 1$)^{2}$ and 87 subjects thought to be at risk of NF2, but not fulfilling criteria, were analysed as below.

\section{MUTATION ANALYSIS}

Genomic DNA samples prepared from peripheral blood were amplified with primers for all 17 exons of the NF2 gene, using primers previously described. ${ }^{512}$ PCR reactions were performed in a total reaction volume of $25 \mu \mathrm{l}$ using $100 \mathrm{ng}$ genomic DNA, $20 \mathrm{pmol}$ of each primer, $200 \mu \mathrm{m}$ of deoxyribonucleoside triphosphate, 0.5 U Tbr polymerase (Northumbria Biologicals Ltd), and $1 \times$ reaction buffer (Northumbria Biologicals Ltd) overlaid with mineral oil. Amplification was performed on a PCR 480 Perkin Elmer Cetus machine (35 cycles of $95^{\circ} \mathrm{C}$ for 90 seconds, $50^{\circ} \mathrm{C}$ for 90 seconds, and $72^{\circ} \mathrm{C}$ for 30 seconds followed by a final elongation step of $72^{\circ} \mathrm{C}$ for 10 minutes).

SSCP analysis was carried out by HydrolinkMDE gel (AT Biochem) electrophoresis according to the supplier's instructions. Samples for SSCP analysis ( $3 \mu \mathrm{l}$ of PCR product) were diluted with $3 \mu$ l of a solution containing $95 \%$ formamide, $20 \mathrm{mmol} / 1 \mathrm{EDTA}, 20 \mathrm{mmol} / \mathrm{l}$ $\mathrm{NaOH}, 0.05 \%$ bromphenol blue, and $0.05 \%$ xylene cyanol, and denatured at $95^{\circ} \mathrm{C}$ for three minutes. Electrophoresis was carried out on 24 $\mathrm{cm}$ vertical and $1 \mathrm{~mm}$ thick gels at a constant voltage of $250 \mathrm{~V}$ for 13-16 hours. Gels were silver stained by sequential incubations in $10 \%$ ethanol and $0.5 \%$ acetic acid $(2 \times 3$ minutes), $0.1 \%$ silver nitrate ( 15 minutes), $1.5 \% \mathrm{NaOH}$ and $0.15 \%$ formaldehyde (20 minutes), and $0.75 \%$ sodium carbonate (10 minutes), and photographed as appropriate.

The last 13 mutations have been identified using a modification of the above technique in the Manchester laboratory. ${ }^{13}$

Patients homozygous for two polymorphic markers within intron $1^{1415}$ were investigated for deletions by hybridising EcoRI and NotI (pulsed field) genomic Southern blots with NEFH (neurofilament heavy chain gene), LIF (leukaemia inhibitory factor gene), and NF2 gene probes (Trueman et al, in preparation).

\section{STATISTICAL ANALYSIS}

Analyses were undertaken using methods appropriate to dependent data, accounting for within family correlation. ${ }^{16}$ For the comparison of proportions, intracluster correlation coefficients were estimated for each end point and an adjusted chi squared statistic calculated; $p$ values were calculated from tables. Age distributions and mean numbers were compared using Wilcoxon rank sum test, with family specific mean ages as the unit of analysis. Two sided $p$ values are reported.

\section{Results}

A total of 54 causative mutations have been identified from the 125 classically affected unrelated subjects (43\%). These consist of 22 nonsense mutations, 11 small frameshift deletions, one in frame deletion, three frameshift insertions, five missense mutations, six splice site mutations, one $3^{\prime}$ untranslated region mutation, and five large deletions (table 2). Index (first affected) cases were unavailable for analysis in 20 families. In the 46 families that have had an affected second generation, 26 mutations (57\%) have been identified. Of the 79 sporadically affected subjects, mutations have only been identified in $28(35 \%)$. This difference reaches statistical significance $\left(\chi^{2}=4.16\right.$, df $\left.1, p<0.05\right)$. Four of the truncating mutations have been found to be in mosaic form, present in $10-38 \%$ of lymphocytes. ${ }^{13}$ One of these mutations (family 10) was transmitted in full form to an affected daughter, although the son who had inherited the high risk chromosome 22 had not inherited the mutation. ${ }^{17}$ Several of the mutations reported here have been previously published. ${ }^{13}{ }^{17-21}$ However, 30/60 are reported here for the first time. The five large deletions are the subject of a further detailed report (Trueman et al, in preparation).

Six causative mutations ( $35 \%)$ have been identified in the 17 cases fulfilling modified criteria (two nonsense mutations, two frameshift deletions, one frameshift insertion, and one missense mutation). Four of 13 cases with unilateral VS + two other NF2 features had mutations, while $2 / 4(50 \%)$ with multiple meningiomas + two other NF2 features were mutation positive. No mutations were found in samples from 87 other patients with features suggestive of NF2, but not fulfilling modified criteria. These varied from unilateral VS at a 
Table 2 NF2 mutations identified in 125 classical and 17 atypical unrelated NF2 families

\begin{tabular}{|c|c|c|c|c|c|c|c|c|}
\hline \multirow[b]{2}{*}{ Family } & \multirow[b]{2}{*}{ Mutation } & \multirow[b]{2}{*}{ Exon } & \multirow[b]{2}{*}{$T$} & \multicolumn{2}{|c|}{ No of affected } & \multicolumn{3}{|l|}{$\operatorname{Ages}(y)$ at } \\
\hline & & & & Cases & Generations & Onset & $H L$ & Diagnosis \\
\hline \multicolumn{9}{|c|}{$\begin{array}{l}\text { Families fulfilling classical criteria } \\
\text { Nonsense mutations }\end{array}$} \\
\hline 1 & G122>A, Trp41>stop & 2 & s & 2 & 2 & 22,11 & 22,15 & 29,11 \\
\hline 2 & C169>T, Arg57>stop ${ }^{116]}$ & 2 & $\mathbf{s}$ & 2 & 2 &,- 22 &,- 22 &,- 23 \\
\hline 3 & C169>T, Arg57>stop & 2 & $\mathbf{s}$ & 2 & 2 &,- 20 &,- 22 &,- 26 \\
\hline 4 & C169>T, Arg57>stop ${ }^{1151}$ & 2 & $\mathbf{s}$ & 1 & 1 & 17 & 18 & 17 \\
\hline 5 & C331>T, Gln111>stop & 3 & $\mathrm{~s}$ & 1 & 1 & 17 & 17 & 18 \\
\hline 6 & C586>T, Arg196>stop ${ }^{[17]}$ & 6 & I & 1 & 1 & 20 & 20 & 28 \\
\hline 7 & C586>T, Arg196>stop & 6 & $\mathbf{s}$ & 2 & 2 & 22,9 & 22,9 & 26,9 \\
\hline 8 & C586>T, Arg196>stop & 6 & I & 1 & 1 & 18 & 18 & 21 \\
\hline 9 & C592>T, Arg198>stop & 6 & $\mathrm{~s}$ & 1 & 1 & 13 & 16 & 16 \\
\hline 10 & C784>T, Arg262>stopt ${ }^{[14]}$ & 8 & $\mathbf{s}$ & 1 & 1 & 19 & 19 & 20 \\
\hline 11 & G949>T, Glu317>stop ${ }^{n}$ & 10 & I & 1 & 1 & 10 & 10 & 31 \\
\hline 12 & C1021>T, Arg341>stop ${ }^{[16]}$ & 11 & $\mathbf{s}$ & 1 & 1 & 13 & 16 & 16 \\
\hline 13 & C1021 > T, Arg341>stop & 11 & $\mathbf{S}$ & 1 & 1 & 17 & 17 & 18 \\
\hline 14 & C1021 > T, Arg341 > stop & 11 & $\mathbf{M}$ & 1 & 1 & 40 & 40 & 40 \\
\hline 15 & C1021>T, Arg341 >stop & 11 & $s$ & 1 & 1 & 14 & 14 & 16 \\
\hline 16 & C1357> T, Gln453>stop & 13 & $\mathbf{s}$ & 1 & 1 & 18 & 19 & 20 \\
\hline 17 & C1396>T, Arg466>stop ${ }^{117]}$ & 13 & $\mathrm{~s}$ & 1 & 1 & 17 & 35 & 30 \\
\hline 18 & $\mathrm{C} 1408>\mathrm{T}, \mathrm{G} \ln 470>$ stop $^{[17]}$ & 13 & $\mathbf{s}$ & 1 & 1 & 27 & 27 & 32 \\
\hline 19 & $\mathrm{C} 1606>\mathrm{T}, \mathrm{G} \ln 536>$ stop & 15 & $M$ & 1 & 1 & 54 & 54 & 54 \\
\hline 20 & $\mathrm{C} 1606>\mathrm{T}, \mathrm{G} \ln 536>$ stop & 15 & $\mathbf{S}$ & 2 & 2 & $16, \mathrm{AS}$ & $16, \mathrm{AS}$ & $22,2^{\star}$ \\
\hline 21 & $\mathrm{C} 1612>\mathrm{T}, \mathrm{G} \ln 538>\operatorname{stop}^{[17]}$ & 15 & $\mathbf{S}$ & 1 & 1 & 6 & 17 & 23 \\
\hline \multicolumn{9}{|c|}{ Frameshifting deletions } \\
\hline 22 & $39 \operatorname{delT}^{\mathrm{n}}$ & 1 & $S$ & 1 & 1 & 19 & 19 & 20 \\
\hline 23 & 40 delCT & 1 & M & 1 & 1 & 30 & 30 & 30 \\
\hline 24 & $40 \mathrm{delCT}^{(17)}$ & 1 & $\mathbf{M}$ & 1 & 1 & 28 & 28 & 32 \\
\hline 25 & $523 \operatorname{delAA}^{\mathrm{n}}$ & 6 & I & 2 & 2 & $28,-$ & $28,-$ & 32,8 \\
\hline 26 & $571 \operatorname{del}^{\mathrm{n}}$ & 6 & $\mathbf{s}$ & 1 & 1 & 21 & 21 & 23 \\
\hline 27 & 713 delC & 8 & $\mathbf{s}$ & 2 & 2 &,- 22 &,- 22 &,- 23 \\
\hline 28 & $770 \mathrm{delC}^{\mathrm{n}}$ & 8 & $\mathbf{s}$ & 1 & 1 & 20 & 24 & 24 \\
\hline 29 & 855 delT $^{n}$ & 9 & I & 2 & 3 & 24,21 & 24,21 & 26,27 \\
\hline 30 & 953 del $\mathrm{T}^{[16]}$ & 10 & $\mathrm{~s}$ & 2 & 2 &,- 3 &,- 3 &,- 4 \\
\hline Framesl & hifting insertions & & & & & & & \\
\hline 31 & 183 insCAAA $^{[16]}$ & 2 & $s$ & 2 & 2 &,- 3 &,- 11 &,- 5 \\
\hline 32 & 1206 ins $^{n}$ & 12 & $s$ & 1 & 1 & 19 & 19 & 20 \\
\hline 33 & 1333 ins $^{n}$ & 12 & $\mathbf{s}$ & 1 & 1 & 18 & 22 & 22 \\
\hline In frame & e deletion & & & & & & & \\
\hline 34 & 355 delTTC ${ }^{177]}$ & 3 & I & 1 & 1 & 18 & 18 & 21 \\
\hline Missens & & & & & & & & \\
\hline 35 & T185>C, Phe62>Ser ${ }^{[16]}$ & 2 & $\mathbf{M}$ & 3 & 4 & $\begin{array}{l}40 \\
40,43 \\
\text { AS25t }\end{array}$ & $\begin{array}{l}40 \\
40,43\end{array}$ & $\begin{array}{l}66 \\
43,43 \\
23^{\star}\end{array}$ \\
\hline 36 & A229 $>\mathrm{G}$, Met $77>\mathrm{Val}^{\mathrm{n}}$ & 2 & I & 3 & 4 & $\begin{array}{l}\text { AS25T } \\
-18\end{array}$ &,- 18 & -48 \\
\hline & & & & & & 24,21 & 24,21 & 24,21 \\
\hline 37 & C1055>T, Thr352>Met $1 \mathrm{~T}^{16]}$ & 11 & $s$ & 2 & 2 & 17,14 & 17,14 & 25,14 \\
\hline 38 & A1237>G, Lys413>Glu ${ }^{(17)}$ & 12 & I & 1 & 1 & 17 & 17 & 18 \\
\hline 39 & T1604>C, Leu535>Pro ${ }^{[17]}$ & 15 & $\mathbf{M}$ & 5 & 10 & $\begin{array}{l}--- \\
61,43\end{array}$ & $\begin{array}{l}--, \\
61,57\end{array}$ & $\begin{array}{l}--- \\
69,58\end{array}$ \\
\hline & & & & & & 52,30 & 52,30 & 72,33 \\
\hline & & & & & & AS30 & AS30 & 30 \\
\hline & & & & & & AS12,AS16† & & $11^{\star}, 15^{\star}$ \\
\hline Splice si & & & & & & & & \\
\hline 40 & 448-1 agTA $>$ aaTA & 5 & I & 3 & 4 & $\begin{array}{l}26 \\
14,21 \\
\text { AS6 }\end{array}$ & $\overline{14,24}$ & $\begin{array}{l}26 \\
20,24\end{array}$ \\
\hline 41 & 599-1AGgt>AGat ${ }^{[17]}$ & 6 & $\mathbf{M}$ & 2 & 3 & $\begin{array}{l}\text { AS6 } \\
25\end{array}$ & 26 & $\begin{array}{l}4^{\star} \\
26\end{array}$ \\
\hline & & & & & & AS $16+, A S 13$ & & $14^{\star}, 10^{\star}$ \\
\hline 42 & $600-2 \mathrm{agGG}>\mathrm{ggGG}^{[17]}$ & 7 & I & 2 & 3 & & & -10 \\
\hline 43 & 600-3cagGG>gagGG & 7 & $M$ & 3 & 4 & $\begin{array}{l}20,19 \\
56\end{array}$ & $\begin{array}{l}20,19 \\
56\end{array}$ & $\begin{array}{l}21,19 \\
56\end{array}$ \\
\hline & & & & & & 2,30 &,- 30 & 20,30 \\
\hline $\begin{array}{l}44 \\
45\end{array}$ & 1123-2agAT>ggAT ${ }^{[17]}$ & 12 & $M$ & 1 & 1 & 35 & 35 & 39 \\
\hline 45 & $1447-1 \mathrm{agCC}>\mathrm{aaCC}^{\mathrm{n}}$ & 14 & $M$ & 3 & 4 & 47 & 47 & 61 \\
\hline $\begin{array}{l}3^{\prime} \text { untra } \\
46\end{array}$ & nslated region & & & & & & & \\
\hline 46 & $\mathrm{C}>\mathrm{T}$ at $1788^{\mathrm{n}}$ & & $M$ & 1 & 1 & 35 & 35 & 38 \\
\hline $\begin{array}{l}\text { Large d } \\
47\end{array}$ & eletions & & & & & & & \\
\hline 47 & 650kb (whole gene) $)^{[18]}$ & & $M$ & 2 & 3 & $\begin{array}{l}23 \\
23 \text {,AS }\end{array}$ & $\begin{array}{l}35 \\
24, \mathrm{AS} 16\end{array}$ & $\begin{array}{l}38 \\
22,12\end{array}$ \\
\hline 48 & $5 \mathrm{~kb}$ (intron 1) & & $\mathbf{M}$ & 5 & 10 &,-- &,-- &,-- \\
\hline & & & & & & $\begin{array}{l}47,29 \\
27,23\end{array}$ & $\begin{array}{l}47,38 \\
27,23\end{array}$ & $\begin{array}{l}66,51 \\
32,23\end{array}$ \\
\hline & & & & & & 24,28 & 24,28 & 24,28 \\
\hline & & & & & & AS,AS & AS16‡,AS12 & $13^{\star}, 9^{\star}$ \\
\hline 49 & $100 \mathrm{~kb}$ & & $M$ & 3 & 5 & & $\overline{31,33}$ & $\overline{31,33}$ \\
\hline & & & & & & $25, \mathrm{AS}$ & 25,AS6 & $25,6^{\star}$ \\
\hline 50 & $60 \mathrm{~kb}$ & & I & 2 & 3 & -1025 & & \\
\hline 51 & $40 \mathrm{~kb}$ & & $\mathrm{~s}$ & 1 & 1 & $\begin{array}{l}19,25 \\
2\end{array}$ & $\begin{array}{l}19,28 \\
13\end{array}$ & $\begin{array}{l}20,30 \\
15\end{array}$ \\
\hline $\begin{array}{l}\text { Mosaic } \\
\text { Nonsen }\end{array}$ & $\begin{array}{l}\text { cases } \\
\text { se }\end{array}$ & & & & & & & \\
\hline 52 & C169>T, Arg57>stop ${ }^{[15 \mid}$ & 6 & $\mathbf{M}$ & 1 & 1 & 41 & 41 & 49 \\
\hline $10 \Omega$ & C784>T, Arg262>stop ${ }^{[14]}$ & 8 & I & 2 & 2 & 23 & 27 & 47 \\
\hline
\end{tabular}




\begin{tabular}{|c|c|c|c|c|c|c|c|c|}
\hline \multirow[b]{2}{*}{ Family } & \multirow[b]{2}{*}{ Mutation } & \multirow[b]{2}{*}{ Exon } & \multirow[b]{2}{*}{$T$} & \multicolumn{2}{|c|}{ No of affected } & \multicolumn{3}{|c|}{$\operatorname{Ages}(y)$ at } \\
\hline & & & & Cases & Generations & Onset & $H L$ & Diagnosis \\
\hline \multicolumn{9}{|c|}{ Frameshift deletions } \\
\hline 53 & 896 delTATG ${ }^{[13]}$ & 10 & $\mathbf{M}$ & 1 & 1 & 21 & 21 & 23 \\
\hline 54 & 1632 delAG ${ }^{[13]}$ & 15 & $\mathbf{M}$ & 1 & 1 & 28 & 28 & 34 \\
\hline \multicolumn{9}{|c|}{$\begin{array}{l}\text { Families fulfilling modified criteria } \\
\text { Nonsense }\end{array}$} \\
\hline 55 & G100>T, Glu34>stop ${ }^{n}$ & 1 & $\mathbf{S}$ & 1 & 1 & 18 & AS & 19 \\
\hline 56 & C586>T, Arg196>stop & 6 & I & 1 & 1 & 18 & - & 22 \\
\hline \multicolumn{9}{|c|}{ Frameshifting deletion } \\
\hline 57 & 40 delCT & 1 & $\mathbf{M}$ & 1 & 1 & 28 & 28 & 32 \\
\hline & $887 \operatorname{delT}^{n}$ & 10 & $\mathrm{~S}$ & 1 & 1 & 3 & - & 4 \\
\hline \multicolumn{9}{|c|}{ Frameshifting insertion } \\
\hline 59 & 1191 ins $^{n}$ & 12 & I & 1 & 1 & 20 & 20 & 24 \\
\hline \multicolumn{9}{|c|}{ Missense } \\
\hline 60 & A317>G, Glu 106>Gly ${ }^{[16]}$ & 3 & $\mathbf{M}$ & 1 & 1 & 20 & 20 & 39 \\
\hline
\end{tabular}

T, type of NF2; HL, hearing loss; AS, asymptomatic.

^DNA diagnosis alone. †DNA diagnosis later found to have VS on scan. $¥ D N A$ diagnosis full neuroaxis MRI imaging normal. \$Family with mosaic affected mother and daughter with germline mutation "Novel mutation.

Ages at onset for the various variables are set out in generation order. Where possible these are shown vertically generation by generation, but for simplicity some generations are shown on the same level. Missing values are shown by -, where information on the person is not considered secure or they died before the study.

young age to patients with meningiomatosis or schwannomatosis with some subjects nearly meeting modified criteria.

The clinical data are summarised in table 3. Forty-two cases from 38 families with truncating mutations (nonsense, small frameshifting insertions, and deletions, excluding mosaics) had an average age at onset of symptoms of 19 years and diagnosis at 22.4 years (mosaic cases were excluded). Fifty-one cases from 17 families with splice site mutations (15 from six), missense mutations (18 from six), and large deletions ( 18 from five) had a later average age of onset of 27.8 years $(p<0.01)$ and at diagnosis of 33.4 years $(p<0.05)$. Subjects with truncating mutations were significantly more likely to have symptoms before 20 years of age $(p<0.001)$ and develop at least two symptomatic CNS tumours in addition to vestibular schwannoma before 30 years $(p<0.001)$. Significant results were also obtained for individual differences between missense, splice site, and large deletion families and truncating mutations for all these parameters $(p<0.0125)$, except for causing symptoms $<20$ years $(\mathrm{p}=0.02$ (missense)-0.06 (splice site)). However, four asymptomatic splice site mutation carriers were excluded as they had not reached 20 years of age. There were also significantly fewer multigenerational families with truncating mutations. Only $9 / 38$ non-mosaic families had resulted in a second affected generation compared to $13 / 17$ of the other mutational types. The four further truncating mutations in mosaic form were associated with milder disease than other similar mutations. As only one case from one family had an in frame deletion, this was excluded from the analysis.

Nine affected subjects from families with nonsense and frameshifting mutations have died. Six died before the study at $37,39,34,35$, 46 , and 30 years of age. Three have died since the start of the study at 23, 32, and 42 years of age. Five subjects with splice site mutations have died at 20,26, 29, 34, and 46 years of age and four with missense mutations have died at $45,64,72$, and 78 years of age. The latter three cases died in old age, deaf but with no diagnosis of NF2 or eighth nerve tumours during life. ${ }^{22}$ Five subjects with large deletions have died at $34,37,34,36$, and 52 years of age. Two with truncating mutations have been diagnosed presymptomatically, one on DNA testing at 2 years of age and the other with bilateral vestibular schwannomas on scan at 9 years of age. Five subjects with splice site mutations were diagnosed without symptoms at $6,9,10$, and 14 years of age on DNA testing and one on scan at 19 years of age. The DNA tested subjects remain CNS tumour free one to two years later. Four with missense mutations have been diagnosed on DNA testing alone aged 10, 13,23 , and 30 years of age. Two of these have had subsequent negative complete neuroaxis

Table 3 Analysis of clinical findings in NF2 patients with frameshift versus other mutation types

\begin{tabular}{|c|c|c|c|c|c|c|}
\hline Feature & $\begin{array}{l}\text { Nonsense or } \\
\text { frameshift mutations }\end{array}$ & $(M)$ & $\begin{array}{l}\text { Splice site } \\
\text { mutations }\end{array}$ & $\begin{array}{l}\text { Missense } \\
\text { mutation }\end{array}$ & $\begin{array}{l}\text { Large } \\
\text { deletions }\end{array}$ & p value \\
\hline Families & 38 & 4 & 6 & 6 & 5 & \\
\hline Patients & 42 & 4 & 15 & 18 & 18 & \\
\hline Current mean age $(y)$ & 24 & 41 & 29 & 39 & 28 & \\
\hline Mean age at onset (y) & 19 & 28 & 26 & 32 & 25 & 0.0072 \\
\hline Mean age at hearing loss & 23 & 29 & 30 & 36.5 & 28 & NS \\
\hline$\%$ presenting before 20 years & 68 & 0 & 36 & 27 & 21 & $<0.001$ \\
\hline Mean age at diagnosis & 22.5 & 37 & 31 & 40 & 30 & 0.0313 \\
\hline$\%$ with $>1$ non-VS symptomatic tumour $<30$ years & 67 & 0 & 11 & 10 & 14 & $<0.001$ \\
\hline$\%$ cataract & 60 & 25 & 45 & 42 & 27 & NS \\
\hline$\%$ with meningioma (and mean No) & $68(2)$ & $25(1)$ & $21(0.7)$ & $28(0.5)$ & $17(0.3)$ & 0.0043 \\
\hline$\%$ with spinal tumours (mean) & $70(3.3)$ & $50(2)$ & $23(0.3)$ & $28(0.5)$ & $28(0.4)$ & 0.0026 \\
\hline$\%$ with skin tumours (mean) & $90(5.8)$ & 0 & $30(0.5)$ & $20(2)$ & $47(1.2)$ & 0.0045 \\
\hline
\end{tabular}

(M)=mosaic

*Truncating versus non-truncating mutations allowing for intrafamilial variation. 
MRI at 16 and 25 years of age, although MRI in a third showed a small unilateral vestibular schwannoma at 30 years of age. Seven subjects with large deletions were diagnosed presymptomatically, four on MRI scans at 12, 22, 25, and 29 years of age and three on DNA alone at 6,9 , and 13 years of age. The 13 year old has had a cranial MRI at 16 years which showed bilateral $<1 \quad \mathrm{~cm}$ asymptomatic vestibular schwannomas. Thus, only $2 / 18$ subjects diagnosed presymptomatically had nonsense or frameshifting mutations even though these are the most common abnormality.

Mean age at onset of symptoms, hearing loss, and diagnosis in the 104 classically affected NF2 cases with no identified mutation was $23.4,25.5$, and 28 years respectively. This is not fundamentally different from the nontruncating mutations, but significantly later than for frameshift and nonsense mutations.

\section{Discussion}

Since the first reports of germline mutations in NF2, there have been attempts to establish a link between the specific NF2 mutation and the disease phenotype..$^{7-10181922}$ A general impression was that protein truncating mutations produced a more severe phenotype while certain splice site and missense mutations were associated with mild disease. ${ }^{7181922}$ Two recent papers have confirmed this impression on larger surveys of mutation proven subjects. ${ }^{89}$ However, clear statistical evidence for this has only been provided for data on age at onset, diagnosis, and hearing loss between nonsense and frameshifting mutations and splice site mutations. ${ }^{8}$ The present study confirms the age related differences between splice site and truncating mutations as well as providing statistical evidence for the first time for a milder disease course in families with missense mutations and large deletions. While some splice site mutations could lead to the production of a truncated protein by allowing read through of intronic sequence and introduction of a premature stop codon, and nonsense mutations could be ameliorated by skipping of the affected exon, we believe the subdivision is in general accurate. The weighted analysis allowing for intrafamilial correlation also provided significant results for presence and number of meningiomas, spinal tumours, and skin tumours in contrast to the previous report. ${ }^{8}$ Although statistical evidence for a difference between 28 cases with protein truncating mutations and 16 cases from three families with single amino acid changes was found in one study, ${ }^{9}$ this was based on classification into disease type alone. No specific data on age and tumour differences were given. The classification of subjects into mild and severe phenotypes is somewhat arbitrary and in many cases not possible, thus the further breakdown into intermediate or moderate cases. ${ }^{9}$ Nonetheless the data from the three families with single amino acid changes appears convincing with many asymptomatic mutation carriers, including one with negative full neuroaxis imaging in their thirties. ${ }^{9}$ This is comparable with our own findings of MRI negative missense mutation carriers. The large deletions are likely to lead to complete absence of protein product as they affect the 5 ' end of the gene. We have previously reported $1 / 5$ of these as being mildly affected ${ }^{21}$ and the original report on cloning the NF2 gene relied on a $40 \mathrm{~kb}$ deletion in a mildly affected family. ${ }^{6}{ }^{8}$ This latter deletion causes an in frame deletion of two exons and could therefore produce a stable protein product. It is possible to hypothesise that mutations/ deletions which give rise to a near normal protein product or no protein product are associated with mild disease, whereas those that cause a truncated protein cause severe disease. This hypothesis has previously been put forward for familial adenomatous polyposis. ${ }^{23}$ Whether abnormal binding of the wild type protein by a truncated protein could cause a similar pattern in NF2 remains to be proven.

In addition to the data on age at onset there appears to be a clear effect on genetic fitness; only $9 / 38$ families with nonsense or frameshifting mutations had resulted in a second affected generation, whereas $13 / 17$ of the other mutational types resulted in multigenerational families. This difference was not seen in a report of 21 mutations, ${ }^{8}$ but $8 / 8$ splice site or missense mutations where family history was known were multigenerational, compared to only $6 / 22$ truncating mutations in another report. ${ }^{9}$ This difference was not specifically referred to in the report although comments were made about the small number of subjects from families with truncating mutations who were diagnosed presymptomatically. ${ }^{9}$ This is very similar to our own findings where only $2 / 18$ presymptomatic diagnoses were made in the truncating mutation families. This could of course be partly explained by the smaller family sizes, but earlier age of onset would be another major contributing factor.

This report documents the NF2 phenotype in 60 unrelated, mutation proven families compared to a combined 57 from the two previous largest reports. ${ }^{89}$ One report did not give clinical data on six further families. ${ }^{9}$ However, the mutation detection rate in the present report is low (43\%) compared to $66 \%$ and $56 \%$ in the two previous large studies, ${ }^{89}$ although better than in two others. ${ }^{7}{ }^{10}$ It is not clear why this should be the case as similar techniques were used. However, the present study has a high number of sporadic cases which could represent low level mosaicism. ${ }^{13}$ Detection rates in our familial cases (56\%) were comparable to the other studies. ${ }^{8}$ We have previously reported the four cases of proven mosaicism ${ }^{131718}$ and it does appear that these are associated with a milder phenotype. It is also possible that the failure to detect mutations in more mildly affected cases in a previous study ${ }^{8}$ could have been partly explained by mosaicism. There is currently no evidence to suggest that there are NF2 cases caused by mutations at another locus and all our families with no proven mutation are consistent with linkage to NF2.

A similar proportion of sporadic patients (35\%) fulfilling modified NF2 criteria compared to sporadic classical disease were found 
to have mutations. Although the numbers were small this would suggest that modified criteria are not overinclusive. The presence of a unilateral VS would make schwannomatosis not caused by NF2 very unlikely ${ }^{24}$ and the presence of at least two NF2 manifestations in patients with multiple meningiomas would also discount overlap with meningiomatosis. However, it is likely that these criteria will identify a number of mosaic cases, as has been predicted for classical sporadic disease. ${ }^{13}$

A number of mutations are reported here for the first time. Fifteen are novel, but we have found three further mutations each of the C586 $>\mathrm{T}$ and $\mathrm{C} 1021>\mathrm{T}$ nonsense mutations making these "warm" spots in the NF2 gene. The C1021>T mutation has been reported in at least 10 further families ${ }^{7-9}$ making it the most common NF2 mutation. We have also confirmed the high frequency of $\mathrm{C}>\mathrm{T}$ transitions at CGA codons. ${ }^{25}$ These occurred in $15 / 125$ (12\%) classically affected cases, with other $\mathrm{C}>\mathrm{T}$ transitions occurring in a further $4 \%$ (5). There is no evidence that these are founder mutations, with most cases being de novo. All the other nonsense and frameshifting mutations would be predicted to give rise to a truncated protein product and it is of note that our most 3 ' truncating mutation in exon 15 gives rise to classical disease. There is no real evidence to suggest that the more 3 ' mutations produce a milder form of NF2. The only new missense mutation reported here (A229>G) segregates with disease and has not been found in any normal samples tested or reported as a polymorphism elsewhere. The same is true for the exon 5 and 7 splice site mutations reported here for the first time. There was one mutation identified in the $3^{\prime}$ untranslated region. The effect of this mutation is unknown. In contrast to a previously reported mutation in this region, ${ }^{9}$ the phenotype was mild. The large deletions will be reported in detail elsewhere (Trueman et al, in preparation).

This report has confirmed the previously described genotype/phenotype correlations in NF2. In addition these have been extended to include families with large deletions which, in general, have a milder disease than truncating mutations. However, caution must be exercised in giving advice to families based on the identification of a truncating or non-truncating mutation in a single person. Even in established families there is still significant intrafamilial variability in disease course. Indeed monozygotic twins with NF2 can have some variation in tumour burden. ${ }^{26}$ Nonetheless the identification of missense mutations, splice site mutations, and large deletions in some families is clearly consistent with a milder phenotype and could lead to different management decisions. ${ }^{27}$

We would like to thank all the clinicians who have informed us of their families with NF2, especially Dr S Huson, Mr T King Professor R Ramsden, and Mr R Lye. Previous laboratory work has been carried out by Dr D Bourn, $S$ Mason, and $S$ Tekes.
This work has been supported by grants from the Medical Research Council, Cancer Research Campaign, and the National Neurofibromatosis Association.

1 Kanter WR, Eldridge R, Fabricant R, Allen JC, Koerber T. Central neurofibromatosis with bilateral acoustic neuroma. Genetic, clinical and biochemical distinctions from peripheral neurofibromatosis. Neurology 1980;30:851-9.

2 Evans DGR, Huson SM, Donnai D, et al. A clinical study of type 2 neurofibromatosis. $Q \mathcal{F}$ Med 1992;84:603-18.

3 Parry DM, Eldridge R, Kaiser-Kupfer MI, Bouzas EA, Pikus A, Patronas N. Neurofibromatosis 2 (NF2): clinical characteristics of 63 affected individuals and clinical evidence for heterogeneity. Am $\mathcal{F}$ Med Genet 1994;52:4501 .

4 National Institutes of Health Consensus Development Conference Statement on Neurofibromatosis. Neurofibromatosis Res Newsl 1987;3:3-6.

5 Rouleau GA, Merel P, Lutchman $M$, et al. Alteration in a new gene encoding a putative membrane-organizing protein causes neurofibromatosis type 2. Nature 1993;363: 515-21.

6 Troffater JA, MacCollin MM, Rutter JL, et al. A novel moesin-, ezrin-, radixin-like gene is a candidate for the neurofibromatosis 2 tumor suppressor. Cell 1993;72:791800.

7 Merel P, Hoang-Xuan K, Sansom M, et al. Screening for germ-line mutations in the NF2 gene. Genes Chrom Cancer 1995;12:117-27.

8 Parry DM, MacCollin M, Kaiser-Kupfer MI, et al. Germ-line mutations in the neurofibromatosis 2 gene: correlations with disease severity and retinal abnormalities. Am f Hum Genet 1996;59:529-39.

9 Ruttledge MH, Andermann AA, Phelan CM, et al. Type of mutation in the neurofibromatosis type 2 gene (NF2) frequently determines severity of disease. Am $\mathscr{f}$ Hum Genet 1996;59:331-42.

10 Kluwe L, Bayer S, Baser ME, et al. Identification of NF2 germline mutations and comparison with neurofibromatosis 2 phenotypes. Hum Genet 1996;98:534-8.

11 Mautner VF, Lindenau M, Baser ME, et al. The neuroimaging and clinical spectrum of neurofibromatosis 2 . Neurosur gery 1996;38:880-5.

12 Jacoby LB, MacCollin MM, Louis DN, et al. Exon scanning for mutation of the NF2 gene in schwannomas. Hum Mol Genet 1994;3:413-19.

13 Evans DGR, Trueman L, Wallace A, Strachan T. Mosaicism in classical NF2: a common mechanism for sporadic disease in tumour prone syndromes? Am $f$ Hum Genet (submitted)

14 Bourn D, Strachan T. Highly polymorphic dinucleotide repeat at the NF2 gene. Hum Genet 1995;95:712

15 Evans DGR, Mason S, Huson SM, Ponder M, Harding AK, Strachan T. Spinal and cutaneous schwannomatosis is a variant form of type 2 neurofibromatosis: a clinical and molecular study. $\mathcal{F}$ Neurol Neurosurg Psychiatry 1997;62 361-6.

16 Donner A, Klar N. Methods for comparing event rates in intervention studies when the unit of allocation is a cluster. Am F Epidemiol 1994;140:279-89.

17 Biljsma EK, Wallace AJ, Evans DGR. Misleading linkage results in an NF2 presymptomatic test owing to mosaicism. 7 Med Genet 1997;34:934-6.

18 Bourn D, Carter SA, Evans DGR, Goodship J, Coakham H, Strachan T. A mutation in the neurofibromatosis type 2 tumor-suppressor gene, giving rise to widely different clinical phenotypes in two unrelated individuals. Am 7 Hum Genet 1994;55:69-73.

19 Bourn D, Carter SA, Mason S, Evans DGR, Strachan T. Germline mutations in the neurofibromatosis type 2 tumour suppressor gene. Hum Mol Genet 1994;3:813-16.

20 Bourn D, Evans G, Mason S, Tekes S, Trueman L, Strachan T. Eleven novel mutations in the NF2 tumour suppressor gene. Hum Genet 1995;95:572-4.

21 Watson C, Gaunt L, Evans DGR, Harris R, Strachan T. A disease associated germline deletion maps the type 2 neurofibromatosis (NF2) gene between the Ewing sarcom region and the leukaemia inhibitory factor (LIF) locus. Hum Mol Genet 1993;2:701-4.

22 Evans DGR, Bourn D, Wallace A, Ramsden RT, Mitchell $\mathrm{JD}$, Strachan T. Diagnostic issues in a family with late onset type 2 neurofibromatosis. $¥$ Med Genet 1995;32:470-4.

23 Su LK, Johnson KA, Smith KJ, et al. Association between wild-type and mutant APC gene products. Cancer Res 1993;53:2728-31

24 MacCollin M, Woodfin W, Kronn D, Short MP. Schwannomatosis: a clinical and pathological study. Neurology 1996;46:1072-9.

25 Sainz S, Figuero K, Baser ME, Mautner VF, Pulst S. High frequency of nonsense mutations in the NF2 gene caused by $\mathrm{C}$ to $\mathrm{T}$ transitions in five CGA codons. Hum Mol Gene 1995;4:137-9.

26 Baser ME, Ragge NK, Riccardi V, Janus T, Gantz B, Pulst S. Phenotypic variability in monozygotic twins with neurofibromatosis 2. Am $\mathcal{F}$ Med Genet 1995;57:A54.

27 Evans DGR, Ramsden R, Huson SM, et al. Type 2 neurofibromatosis: the need for supraregional care. Laryngol Otol 1993;107:401-6. 